\title{
Selection of Solar Cell based on TOPSIS Method
}

\author{
Yu Zeyuan \\ North China Electric Power University, Baoding, 071000 \\ E-mail: yu385979783@gmail.com
}

\begin{abstract}
In this paper, various kinds of solar cell are compared and analyzed with TOPSIS method and sunny model by starting from three aspects, namely gross generation, unit cost of generated energy and return on investment. According to the results, when more attention is paid to environmental factors, the mono-crystalline silicon battery receives better comprehensive benefits than polycrystalline silicon battery and thin-film battery; and when more attention is paid to economic factors, thin-film battery receives better comprehensive benefits than mono- crystalline silicon battery and polycrystalline silicon. As a result, it provides basis for the selection of solar cell in various regions.
\end{abstract}

Index Terms - Sunny Model, TOPSIS method, solar cell, comprehensive benefits

\section{Introduction}

Solar energy radiation received by the earth surface can satisfy more than 10000 times of the global energy demand. The radiation received by each square meter of the earth surface can generate $1700 \mathrm{k} \mathrm{W} \cdot \mathrm{h}$. According to the data from international energy agency, if solar photovoltaic system is allocated in $4 \%$ of the desert throughout the world, it will satisfy the global energy demand. Solar photovoltaic enjoys a broad development space, with great potential [1]. China is severely short of power. Thermal power consumes large amounts of coal, which can cause serious air pollution. However, solar energy, as a clean energy, will have a profound and lasting significance when properly utilized.

The power of thin-film battery and mono-crystalline silicon battery is compared by Jinglong Chai [2]. Specific power generating capacity is compared by using Software PVsyst to simulate different kinds of solar battery to analysis their advantages and disadvantages by Zhenquan $\mathrm{Li}$ [3]. Conversion efficiency of the solar battery, maturity of technology and cost of the production are compared by Weimin Xu [4]. However they only compare them In one aspect

TOPSIS method is an effective multi-criteria decision method, aiming to construct ideal solution and negative ideal solution, apply near-ideal solution, and deviate from the negative ideal solution, as the judgment basis, thus to evaluate the references of each plan. The traditional major indexes measuring the efficiency of various solar cells are gross generation, unit cost of generated energy and rate of return on investment, which reflecting the advantages and disadvantages of solar cell from one aspect, and it is not complete. In this paper, TOPSIS method is adopted to evaluate each solar cell comprehensively, thus to consider the optimal selection of solar cell.

\section{Calculation Principle and Method}

2.1 Calculation of the total solar radiation on the south side of a house

According to the sunny model, as well as the annual hourly parameters provided by the weather bureau and data of radiation intensity in each direction, the daily hourly solar radiation on the south elevation of a house is worked out by taking advantage of MATLAB programming, considering the real situation of silicon cell and thin-film battery. On that basis, the annual solar radiation of unit area on the south elevation of a house is calculated.[5]

\subsection{Calculation of evaluation index}

\subsubsection{Calculation of generating cost}

The cost of the plan is calculated by combining the optimal method of photovoltaic module and inverter. It is considered that the generating cost mainly consists of two parts, namely the solar panel and inverter, and the calculation equation is shown as follows.

$$
S_{i j}=(m \times n) p_{i} s_{i}+s_{j}
$$

( $S_{i j}$ refers to the total cost of the $\mathrm{i}^{\text {th }}$ battery and the $\mathrm{j}^{\text {th }}$ inverter, $\mathrm{m}$ refers to the number of solar panel in series, $\mathrm{n}$ refers to the number of solar panel in parallel, $p_{i}$ refers to the price of the $\mathrm{i}^{\text {th }}$ battery, $s_{i}$ refers to the area of the $\mathrm{i}^{\text {th }}$ battery, $s_{j}$ refers to the cost of the $\mathrm{j}^{\text {th }}$ inverter)

\subsubsection{Calculation of total generation}

Considering the practical generation of solar panel, it usually lasts for 35 years, and there may be loss after serving for a period of time. As a result, in this paper, the 35-year gross generation is calculated as follows, in the first 10 years, it is $100 \%$, in the next 15 years, it is $90 \%$, and in the last 10 years, it is $80 \%$. The calculation equation is shown as follows.

$$
G_{i j}=(10 \times 100 \%+15 \times 90 \%+10 \times 80 \%) H_{i} \times(m \times n) \eta_{i} \eta_{j}
$$

( $G_{i j}$ refers to the generation of the $\mathrm{i}^{\text {th }}$ battery and the $\mathrm{j}^{\text {th }}$ inverter, $H_{i}$ refers to the radiation of the $\mathrm{i}^{\text {th }}$ solar panel in unit area, $m$ refers to the number of solar panel in series, $n$ refers to the number of solar panel in parallel, $\eta_{i}$ refers to the conversion efficiency of the $\mathrm{i}^{\text {th }}$ battery, $\eta_{j}$ refers to the conversion efficiency of the $\mathrm{j}^{\text {th }}$ converter) 


\subsubsection{Calculation of net income}

The net income equals the deduction of generating cost from the total income. Considering the real situation of solar power generation benefit, it is calculated according to 0.5 Yuan $/ \mathrm{KW} \cdot \mathrm{h}$, and the calculation equation is shown as follows:

$$
N_{i j}=0.5 G_{i j}-S_{i j}
$$

( $N_{i j}$ refers to the 35 -year net income of the $\mathrm{i}^{\text {th }}$ battery and $\mathrm{j}^{\text {th }}$ inverter)

\subsubsection{Calculation of unit generating cost}

The unit generating cost equals the proportion of total income and gross generation, and the calculation equation is shown as follows.

$$
P_{y j}=0.5-\frac{S_{y j}}{G_{y j}}
$$

( $P_{i j}$ refers to the unit generating cost of the $\mathrm{i}^{\text {th }}$ battery and $\mathrm{j}^{\text {th }}$ inverter)

\subsubsection{Calculation of investment payback period}

The investment payback period refers to the time required by recovering the cost, and the calculation equation is shown as follows:

$$
T_{i j}=\left\{\begin{array}{l}
\frac{63 S_{i j}}{G_{i j}}, 0 \leq x \leq 10 \\
\frac{70 S_{i j}}{G_{i j}}-\frac{10}{9}, 10<x \leq 23.5 \\
\frac{315 S_{i j}}{4 G_{i j}}-\frac{47}{8}, x>23.5
\end{array}\right.
$$

In which:

$$
x=\frac{S_{i j}}{\frac{G_{i j}}{31.5} \times 0.5}
$$

( $T_{i j}$ refers to the investment payback period of the $\mathrm{i}^{\text {th }}$ battery and $\mathrm{j}^{\text {th }}$ inverter)

\subsubsection{Calculation of return on investment}

The return on investment is the reciprocal of investment payback period, standing for the annual income

$$
R_{\mathrm{ij}}=\frac{1}{T_{i j}} \times 100 \%
$$

( $R_{\mathrm{ij}}$ refers to the return on investment of the $\mathrm{i}^{\text {th }}$ battery and $\mathrm{j}^{\text {th }}$ inverter)

\subsection{Comprehensive assessment based on TOPSIS method}

Technique for order preference by similarity to an ideal solution (shortened as TOPSIS) is a near-ideal ordering method, which can find out the optimal and inferior solutions in the limited multi-objective decisions. And then the distance and closeness degree between the evaluation target and the optimal or inferior solution are calculated, and it will be sorted according to the closeness degree of limited plans and ideal objective.

The general procedures of TOPSIS is shown as follows:

Step1: suppose the plan set $A=\left\{A_{1}, A_{2}, \cdots A_{n}\right\}$, evaluation index set $B=\left\{B_{1}, B_{2}, \cdots B_{m}\right\}$, in which, the number of plans $n$ and the number of index $m$ are all limited values. The initial matrix $R$ is constructed:

$$
R=\left[\begin{array}{cccc}
r_{11} & r_{12} & \cdots & r_{1 m} \\
r_{21} & r_{22} & \cdots & r_{2 m} \\
\vdots & \vdots & \ddots & \vdots \\
r_{n 1} & r_{n 2} & \cdots & r_{n m}
\end{array}\right]
$$

Step 2: Same trending of elevation index

When evaluating with TPOSIS, all the indexes should be in the same direction (same trending), which will turn the high optimal index into low optimal index, or in the opposite way. Generally, the latter method will be adopted.

To turn the low optimal index into the high optimal index, namely the common reciprocal method

$$
r_{i j}^{\prime}=\frac{1}{r_{i j}}
$$

The matrix after same trending will be obtained

Step 3: Dimensionless standard processing will be conducted for the initial matrix after the same trending:

$$
y_{i j}=\frac{r_{i j}}{\sqrt{\sum_{i=1}^{n} r_{i j}^{2}}}
$$

The standardized matrix will be obtained:

$$
Y_{n \times m}=\left\{y_{i j}\right\}
$$

Step 4: according to the weight set of the evaluation index $\varpi=\left\{\varpi_{1}, \varpi_{2}, \cdots \varpi_{m}\right\}$, the weighted standard matrix will be created:

$$
V=\left[\begin{array}{cccc}
V_{11} & V_{12} & \cdots & V_{1 m} \\
V_{21} & V_{22} & \cdots & V_{2 m} \\
\vdots & \vdots & \ddots & \vdots \\
V_{n 1} & V_{n 2} & \cdots & V_{n m}
\end{array}\right]=\left[\begin{array}{cccc}
\varpi_{1} y_{11} & \varpi_{2} y_{12} & \cdots & \varpi_{m} y_{1 m} \\
\varpi_{1} y_{21} & \varpi_{2} y_{22} & \cdots & \varpi_{m} y_{2 m} \\
\vdots & \vdots & \ddots & \vdots \\
\varpi_{1} y_{n 1} & \varpi_{2} y_{n 2} & \cdots & \varpi_{m} y_{n m}
\end{array}\right]
$$

Step 5: the optimal and inferior solution $A^{+}$and $A^{-}$ will be determined.

$$
A^{+}=\left[V_{1}^{+}, V_{2}^{+}, \cdots V_{m}^{+}\right]
$$

where $V_{j}^{+}=\max \left\{V_{1 j}, V_{2 j}, \cdots V_{m j}\right\}, j=1,2, \cdots m$

$A^{-}=\left[V_{1}^{-}, V_{2}^{-}, \cdots V_{m}^{-}\right]$where, 


$$
V_{j}^{-}=\min \left\{V_{1 j}, V_{2 j}, \cdots V_{m j}\right\}, j=1,2, \cdots m
$$

Step 6: the distance of all the indexes $D^{+}$and $D^{-}$from the optimal and inferior solution $A^{+}$and $A^{-}$are calculated, and Euclidean distance will be adopted.

$$
D_{i}^{+}=\sqrt{\sum_{j=1}^{m}\left(V_{i j}-V_{j}^{+}\right)^{2}} \quad D_{i}^{-}=\sqrt{\sum_{j=1}^{m}\left(V_{i j}-V_{j}^{-}\right)^{2}}
$$

Step 7: the closeness distance $C_{i}^{*}$ of each solution $A_{i}$ from the optimal solution will be calculated, $0 \leq C_{i}^{*} \leq 1$.

$$
C_{i}^{*}=\frac{D_{i}^{-}}{D_{i}^{+}+D_{i}^{-}}, \quad i=1,2, \cdots n
$$

Step 8: it will sort in descending order according to the closeness degree $C_{i}^{*}$, the greater it is, the closer to the optimal level solution $A_{i}$ will be (namely the optimal solution $A^{+}$), and the smaller $C_{i}^{*}$ is, the closer to inferior level solution $A_{i}$ will be.

\section{Calculation Result and Analysis}

The data in this paper comes from the meteorological data of Datong City in Shanxi Province, and the total annual solar radiation in unit area on the south side of a house is obtained after calculation by Matlab, as shown in table one:

Table 1 annual solar radiation od unit area in the south elevation of the house

\begin{tabular}{|l|c|c|c|}
\hline & $\begin{array}{c}\text { Mono-crystalline } \\
\text { silicon battery }\end{array}$ & $\begin{array}{c}\text { Poly-crystalline } \\
\text { silicon battery }\end{array}$ & $\begin{array}{c}\text { Thin-film } \\
\text { battery }\end{array}$ \\
\hline $\begin{array}{l}\text { Generating capacity } \\
\text { of south elevation } \\
\left(\mathrm{W} / \mathrm{m}^{2}\right)\end{array}$ & 1158656.9 & 1158656.9 & 1191624.4 \\
\hline
\end{tabular}

For the convenience of comparison, two kinds of batteries with different performance and six inverters are selected for each solar cell, and the performance parameters are shown as follows.

Table 2 parameters of solar panel

\begin{tabular}{|c|c|c|c|c|c|c|}
\hline PV battery & $\begin{array}{c}\text { Module power } \\
(\mathrm{w})\end{array}$ & $\begin{array}{c}\text { Module size } \\
(\mathrm{mm} \times \mathrm{mm})\end{array}$ & $\begin{array}{c}\text { Open-circuit } \\
\text { voltage (Voc) }\end{array}$ & $\begin{array}{c}\text { Short-circuit } \\
\text { voltage (Isc/A) }\end{array}$ & $\begin{array}{c}\text { Conversion } \\
\text { efficiency } \eta(\%)\end{array}$ & Price (Yuan/Wp) \\
\hline Mono-crystalline silicon battery 1 & 215 & $1580 \times 808 \times 40$ & 46.1 & 5.79 & $16.84 \%$ & 14.9 Yuan/Wp \\
\hline Mono-crystalline silicon battery 2 & 245 & $1650 \times 991 \times 40$ & 37.73 & 8.58 & $14.98 \%$ & 14.9 Yuan/Wp \\
\hline Poly-crystalline silicon battery 1 & 265 & $1650 \times 991 \times 40$ & 37.91 & 9.01 & $16.21 \%$ & $12.5 \mathrm{Yuan} / \mathrm{Wp}$ \\
\hline Poly-crystalline silicon battery 2 & 295 & $1956 \times 992 \times 50$ & 45.1 & 8.57 & $15.20 \%$ & 12.5 Yuan/Wp \\
\hline Thin-film battery 1 & 58 & $1321 \times 711 \times 20$ & 62.3 & 1.54 & $6.17 \%$ & 4.8 Yuan/Wp \\
\hline Thin-film battery 2 & 4 & $615 \times 180 \times 16.7$ & 12.6 & 0.7 & $3.63 \%$ & 4.8 Yuan/Wp \\
\hline
\end{tabular}

Table 3 parameters of inverter

\begin{tabular}{|l|c|c|c|c|}
\hline Type & Rated current (A) & Allowed input voltage range (V) & inversion efficiency (80\% resistive load) & Reference price (Yuan/ machine) \\
\hline SN1 & 24 & $42 \sim 64$ & $86 \%$ & 4500 \\
\hline SN2 & 115 & $42 \sim 64$ & $90 \%$ & 15000 \\
\hline SN3 & 30 & $99 \sim 150$ & $90 \%$ & 10200 \\
\hline SN4 & 5 & $180 \sim 300$ & $94 \%$ & 4500 \\
\hline SN5 & 25.3 & $180 \sim 300$ & $94 \%$ & 15300 \\
\hline SN6 & 40 & $250 \sim 800$ & $97.3 \%$ & 43750 \\
\hline
\end{tabular}

Considering the practical situation of architecture in Datong, in the following part, one type of architecture will be taken as an example, for calculating the total income of the each solar panel with the optimal inverter.

The results are shown as follows

\begin{tabular}{|c|c|c|c|c|c|c|c|}
\hline & Inverter & Cost (Yuan) & $\begin{array}{c}\text { Generating } \\
\text { capacity (kwh) }\end{array}$ & $\begin{array}{c}\text { Income } \\
\text { (Yuan) }\end{array}$ & $\begin{array}{c}\text { Unit generating } \\
\text { cost (Yuan/kwh) }\end{array}$ & $\begin{array}{c}\text { Payback } \\
\text { period (year) }\end{array}$ & $\begin{array}{c}\text { Return on } \\
\text { investment }\end{array}$ \\
\hline Mono-crystalline silicon battery 1 & SN3 & 58252.5 & $1.012 * 10^{\wedge} 5$ & 23780 & 0.5755 & 24.1 & $4.15 \%$ \\
\hline Mono-crystalline silicon battery 2 & SN3 & 43054.5 & $7.241 * 10^{\wedge} 4$ & 14876 & 0.5946 & 24.9 & $4.02 \%$ \\
\hline Poly-crystalline silicon battery 1 & SN3 & 40012.5 & $7.836^{*} 10^{\wedge} 4$ & 22675 & 0.5106 & 21.2 & $4.72 \%$ \\
\hline Poly-crystalline silicon battery 2 & SN3 & 43387.5 & $8.719 * 10^{\wedge} 4$ & 26366 & 0.4976 & 20.7 & $4.83 \%$ \\
\hline Thin-film battery 1 & SN1 & 8676 & $2.806 * 10^{\wedge} 4$ & 13772 & 0.3092 & 12.4 & $8.06 \%$ \\
\hline Thin-film battery 2 & SN4 & 7591.2 & $2.088^{\wedge} 10^{\wedge} 4$ & 9116 & 0.3325 & 14.8 & $6.76 \%$ \\
\hline
\end{tabular}


Related parameters of the six batteries are analyzed with $1: 1: 1$, the result is shown as follows; TOPSIS, and it has been discovered that when the weight is

\begin{tabular}{|c|c|c|c|c|c|}
\hline $\begin{array}{c}\text { Mono-crystalline silico } \\
\text { battery1 }\end{array}$ & $\begin{array}{c}\text { Mono-crystalline silicon } \\
\text { battery2 }\end{array}$ & $\begin{array}{c}\text { Poly-crystalline silicon } \\
\text { battery1 }\end{array}$ & $\begin{array}{c}\text { Poly-crystalline silicon } \\
\text { battery2 }\end{array}$ & $\begin{array}{c}\text { Thin-film } \\
\text { battery1 }\end{array}$ & $\begin{array}{c}\text { Thin-film } \\
\text { battery2 }\end{array}$ \\
\hline 0.5636 & 0.3889 & 0.4672 & 0.5252 & 0.4671 & 0.3749 \\
\hline 1 & 5 & 3 & 2 & 4 & 6 \\
\hline
\end{tabular}

The mono-crystalline silicon battery 1 is the best, and it can be learnt that: when the significance of all these factors is equal, the mono-crystalline silicon battery has better benefit. It can be discovered from observing the index of the benefit of mono-crystalline silicon battery that the generated energy of mono-crystalline silicon battery is greater than that of any other types, and it is far greater than that of thin-film battery. When the country encourages green energy, mono-crystalline silicon battery will be a good choice.

When the weight is $1: 2: 1$, the result is shown as follows:

\begin{tabular}{|c|c|c|c|c|c|}
\hline $\begin{array}{c}\text { Mono-crystalline silicon } \\
\text { battery1 }\end{array}$ & $\begin{array}{c}\text { Mono-crystalline silicon } \\
\text { battery2 }\end{array}$ & $\begin{array}{c}\text { Poly-crystalline silicon } \\
\text { battery1 }\end{array}$ & $\begin{array}{c}\text { Poly-crystalline silicon } \\
\text { battery2 }\end{array}$ & $\begin{array}{c}\text { Thin-film } \\
\text { battery1 }\end{array}$ & $\begin{array}{c}\text { Thin-film } \\
\text { battery2 }\end{array}$ \\
\hline 0.4565 & 0.3065 & 0.3869 & 0.4374 & 0.5737 & 0.4949 \\
\hline 3 & 6 & 5 & 4 & 1 & 2 \\
\hline
\end{tabular}

When the weight is 1:1:2, the result is shown as follows

\begin{tabular}{|c|c|c|c|c|c|}
\hline $\begin{array}{c}\text { Mono-crystalline silicon } \\
\text { battery1 }\end{array}$ & $\begin{array}{c}\text { Mono-crystalline silicon } \\
\text { battery2 }\end{array}$ & $\begin{array}{c}\text { Poly-crystalline silicon } \\
\text { battery1 }\end{array}$ & $\begin{array}{c}\text { Poly-crystalline silicon } \\
\text { battery2 }\end{array}$ & $\begin{array}{c}\text { Thin-film } \\
\text { battery1 }\end{array}$ & $\begin{array}{c}\text { Thin-film } \\
\text { battery2 }\end{array}$ \\
\hline 0.4432 & 0.2968 & 0.3762 & 0.4243 & 0.5862 & 0.4632 \\
\hline 3 & 6 & 5 & 4 & 1 & 2 \\
\hline
\end{tabular}

It can be learnt from the above two tables that when more attention is paid to the economic index, the thin-film battery will be the best. Owning to its low cost, and lower demand on generating condition, it is much more applicable for the civil small-scale power generation. When more attention is paid to environmental protection, mono-crystalline silicon battery can be considered. And when more attention is paid to the economic benefit, the thin-film battery can be considered.

\section{Conclusion}

In this paper, a solar cell evaluation system is constructed, which includes economic index and generating index, taking the economic and social benefit of the enterprise into consideration. And then, the solar cell is elevated and selected with TOPSIS. In the end, the feasibility of this model is verified with an example, which provides an effective method for the selection of solar cell.

\section{References}

[1] Junfeng L, Sicheng W, Minji Z. 2007 China Solar PV Report. Beijing: China Environmental Science Press, 2007.

[2] Jinlong $\mathrm{C}, \mathrm{Li}$, Shengming $\mathrm{H}$. Non, monocrystalline solar modules than the power generation capacity compared. Shenzhen University Science \& Engineering, 2005.7, 22(3):226-229.

[3] Zhenquan L, Yunliang X, Liou S P. Several solar modules than the power generation capacity of simulation and comparison. Electrical Equipment, 2010(4):30-32.

[4] Weimin X, Xiange H, Hongbing Z, etal. The principle types of solar cells. power equipment, 2011.3, 25(2):137-140. [5] Lijun C, Liqin M. Solar photovoltaic power plant design and selection of cell components. Inner Mongolia Science Technology and Economy, 2012.10(19): $115-116$

[5] Lu Q, Zhou J. Major cities sunny hourly solar radiation intensity and Solar collectors best angle of simulation. BUILDING SCIENCE, 2012.10, 28(2 Suppl):22-26.

[6] BingKun Y, Fang J. Amorphous silicon thin film solar cell research. Guangzhou Chemical Industry, 2012.4, 40(8):31-34.

[7] Aiping Y. A Novel Model for Dynamic Multi-Attributes Group Decision-Making Based on Vague Set and its TOPSIS Solution. Beijing, China: Proceedings of the 29th Chinese Control Conference, July 29-31, 2010:5539-5543. 